\title{
Análisis de aplicaciones espectrales derivados de imágenes satelitales PerúSAT-1
}

\author{
Analysis of spectral applications derived from images PeruSAT-1 satellite
}

\author{
Roy Andy Giraldo Colonia ${ }^{1}$
}

Recibido: 01/12/2019 - Aprobado: 15/02/2021 - Publicado: 18/06/2021

\begin{abstract}
RESUMEN
El siguiente articulo pretende mostrar las aplicaciones posibles de imágenes satelitales PerúSAT-1 para contribuir a futuros trabajos de Teledetección e Ingeniería, además de ver la utilidad de este sensor nacional. Dada las características espectrales del sensor, se pueden estimar y analizar los índices de vegetación, índice de agua, índice de nieve entre otros, así como un análisis de anomalías espectrales por presencia de óxidos mediante el método de Análisis de Componentes Principales. Sin embargo, la realización del análisis para arcillas, carbonatos y otros minerales es limitado por la ausencia de información en el SWIR Y TIR.
\end{abstract}

Palabras clave: componentes principales; índices espectrales; firma espectral; óxidos; Perú SAT-1.

\begin{abstract}
The following article intends to show the possible applications of satellite images PeruSAT-1 to contribute to future works of Teledetection and Engineering, in addition to seeing the utility of this national sensor. Given the spectral characteristics of the sensor, we can estimate and analyze the vegetation indexes, water index, snow index among others as well as an analysis of spectral anomalies by the presence of oxides by the Principal Components Analysis method. However, the performance of the analysis for clays, carbonates and other minerals is limited by the lack of information in SWIR and TIR.
\end{abstract}

Keywords: principal components; spectral indices; spectral signature; oxides; PerúSat-1. 


\section{INTRODUCCIÓN}

El empleo de la teledetección se encuentra ligado a la resolución tanto temporal, espectral como espacial de las imágenes disponibles. PerúSAT-1 desde el año 2016 permite tener acceso a nivel nacional de imágenes satelitales de alta resolución espacial y la posibilidad de desarrollar investigaciones y aplicaciones en ingeniería. La finalidad del presente estudio es contribuir con la frontera de posibilidades que genera PerúSAT-1 dado su resolución espectral ( 5 bandas), menor a otros sensores (CONIDA, 2021).

Las aplicaciones derivadas de las imágenes PerúSAT-1 del presente estudio son preliminares, por ende, requieren validación sobre el terreno. Sin embargo, se replicó el modelo de análisis de muchos sensores ampliamente validados en el campo de la teledetección como lo son ASTER, SENTINEL-2 y LANDSAT-8 por mencionar algunos.

\section{MÉTODOS}

Para el desarrollo de este estudio, se utilizaron dos imágenes PerúSAT-1 en formato nativo, y se analizó con el software ENVI 5.4.

\section{i. PER1_20170204145653_SEN_MS_000041 \\ ii. PER1_20170417153836_SEN_MS 000659}

Ubicación del área de estudio: En La libertad la ubicación corresponde al valle, desembocadura, del rio Jequetepeque; en Arequipa corresponde al volcán Chachani. Se realizó la corrección geométrica y corrección atmosférica según la metada de las imágenes en mención. Posteriormente se aplicó los índices espectrales a clasificar y finalmente la técnica PCA para identificación de óxidos (PeruSAT1, 2021).

\subsection{Análisis de Componentes Principales (PCA)}

El método PCA es un algoritmo matemático útil en el proceso de imágenes satelitales con el objetivo de transformar "n" número de bandas espectrales con alta correlación a "m" número de bandas espectrales no correlacionadas, donde "n" < "m", y estas se llaman componentes principales. En el presente estudio se aplicó la técnica (Alvaro Penteado Crósta, 1993), (Crosta \& Moore, 1989), (Loughlin, 1991). Valido en la identificación de arcillas y óxidos de hierro (Ver Figura 1).

\subsection{Selección de las bandas de interés}

En el caso de PerúSAT-1,

- Las bandas VNIR (Visible e infrarrojo cercano) cubren regiones de máxima reflectancia y absorción, firma espectral de óxidos de $\mathrm{Fe} 3+$. Análisis viable.

- Las bandas VNIR y SWIR (Infrarrojo de onda corta) cubren regiones de máxima reflectancia y absorción, para minerales que contienen $\mathrm{OH}-$ (arcillas: Jarosita, Alunita, Caolinita). Análisis inviable por falta de espectro.

\section{RESULTADOS}

Posterior a las correcciones se aplicó el software, se obtuvieron las imágenes y capas vector resultantes a partir del proceso de identificación de la firma espectral de interés, generando las aplicaciones derivadas. Estas capas contienen los valores de cada uno de los índices espectrales evaluados y las anomalías espectrales por presencia de óxidos (técnica PCA).

\subsection{Aplicación de Índices Espectrales}

Los índices espectrales son combinaciones de reflectancia superficial a dos o más longitudes de onda que indican abundancia relativa de características de interés. Permiten identificar rasgos físicos de coberturas de vegetación, agua, nieve y alteraciones del terreno, a partir de ellos se obtienen datos apropiados para estudios de ambientes dinámicos a todo tamaño de escala.

3.1.1. Índices de Vegetación: Índice de Vegetación de Diferencia Normalizada (NDVI)

Este índice es una medida óptima de vegetación. El empleo de su formula de diferencia normalizada combinado con

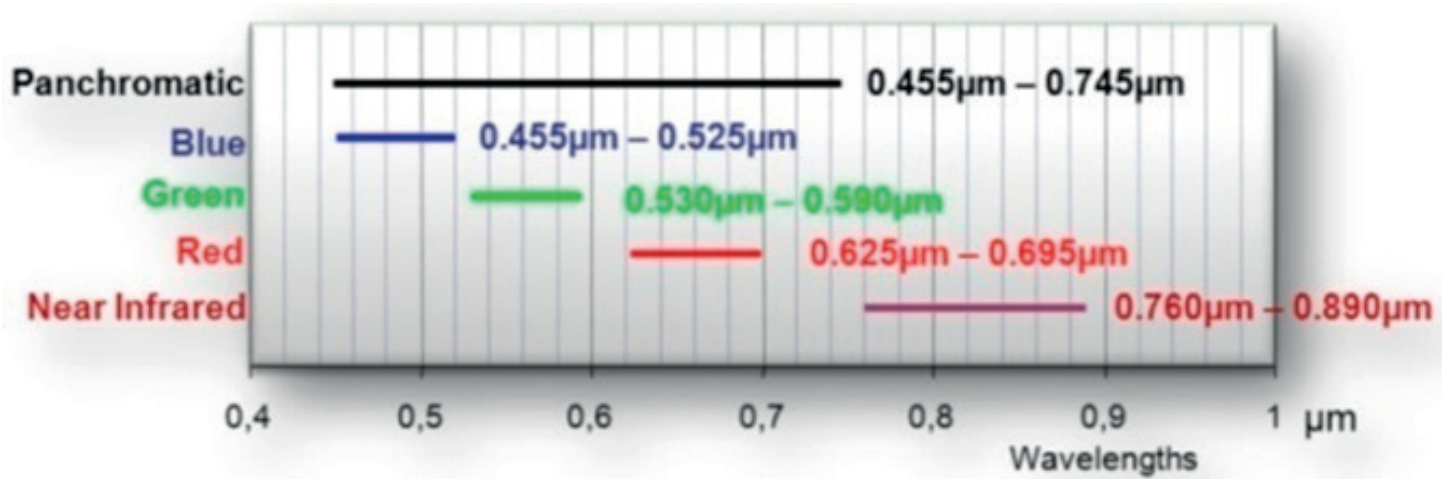

Figura 1. Alcance espectral, PerúSAT-1. 
las regiones más altas de absorción y reflectancia de clorofila la convierten en óptimo en múltiples condiciones. $N D V I=\frac{(\mathrm{NIR}-\mathrm{RED})}{(\mathrm{NIR}+\mathrm{RED})},($ Harris Geospatial Solutions, 2021).

La fluctuación de valores del índice es entre -1 y 1. Valores mayores a 0.1 indican presencia de vegetación, y mientras más alto sea el valor la vegetación está en mejores condiciones.

El NDVI y sus variables índices proporcionaron buenos resultados para imágenes PeruSAT-1, de los cuales el NDVI se aplicó positivamente para zonas de cultivos con una buena resolución. Las otras variables de índices de vegetación viables requieren un análisis más detallado de su aplicabilidad.

- Una de las aplicaciones del NDVI es comparar zonas deforestadas. A través de imágenes de fechas anterior y posterior a la depredación, generando coeficientes multitemporales.

3.1.2. Índice de Agua: Índice de Agua de Diferencia Normalizada (NDWI)

Este índice es sensible a la variación de agua y su contenido, maximiza la reflectancia del agua usando para ello la banda del Infrarrojo Cercano (NIR) y la absorción de la vegetación y de suelo adyacente en la banda del Verde. $N D W I=\frac{(\text { GREEN }- \text { NIR })}{(\text { GREEN }+ \text { NIR })}, \begin{gathered}\text { modificada para analizar } \\ \text { (GREEN }- \text { SWIR })\end{gathered}$ imágenes PeruSAT-1, a partir de: NDWI $=\frac{(\text { GREEN }- \text { SWIR })}{(\text { GREEN }+ \text { SWIR })}$, (Harris Geospatial Solutions, 2021).

El resultado de esta ecuación realza las características acuáticas con los valores más altos, mientras que el suelo y la vegetación terrestre tienen valor de 0 o valores negativos
Proporcionó resultados satisfactorios para imágenes PeruSAT-1 y una mayor respuesta en aguas profundas. El rendimiento de este índice disminuye en zonas de sombra (en base a las imágenes procesadas).

- Una de las aplicaciones del NDWI es comparar las áreas inundadas. A través de imágenes de fechas anterior y posterior al evento disruptor, generando coeficientes multitemporales.

3.1.3. Índice de Nieve: Índice de Nieve de Diferencia Normalizada (NDSI)

Identifica la nieve e incluso el hielo, empleando la alta reflectancia del agua sólido y la absorción en las bandas visible e infrarrojo. Este índice pone de relieve la cubierta de hielo y nieve. NDSI $=\frac{(\text { BLUE }- \text { NIR) }}{(\text { BLUE }+ \text { NIR) }}$, (U.S. Geological Survey, 2021).

Proporcionó buenos resultados para imágenes PeruSAT-1, identificando zonas de hielo y nieve con buena resolución. Es recomendable enmascarar las sombras (valores mínimos del NIR) antes de procesar este índice, de esta manera se obtiene mejores resultados.

- Una de las aplicaciones del NDSI es identificar zonas de retroceso de glaciares. A través de imágenes de fechas anterior y posterior al deshielo, generando coeficientes multitemporales (Ver Figuras 2 - 4).

\subsection{Aplicación de anomalías espectrales}

Anomalías espectrales son respuestas diferentes del espectro electromagnético en determinadas bandas y representan un valor atípico respecto al fondo. Estas longitudes de onda
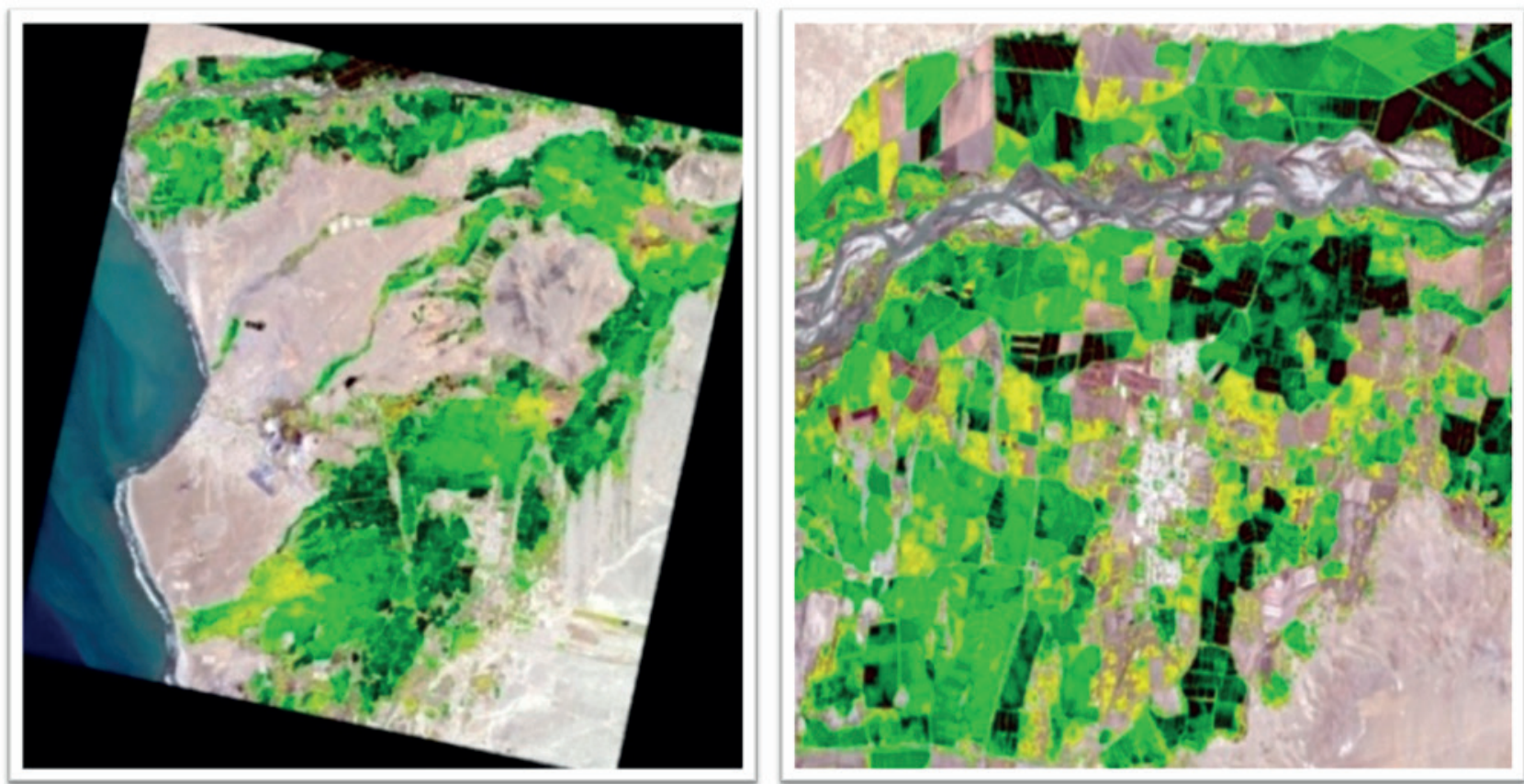

Figura 2. Índice de Vegetación Normalizado NDVI, colores verdes más oscuros representan vegetación más intensa. Resolución espacial var. $2 \mathrm{~m}$ a $10 \mathrm{~m}$ 

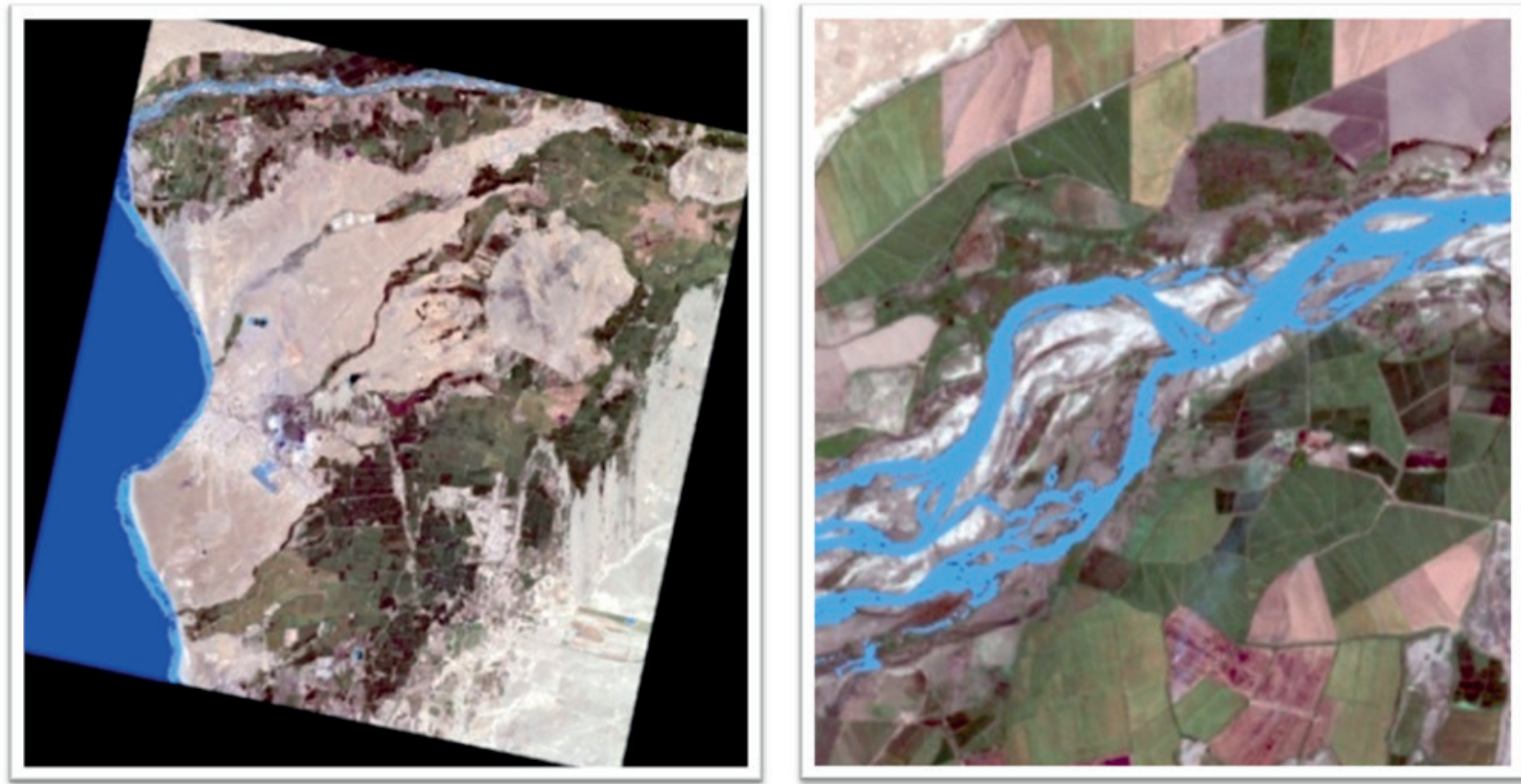

Figura 3. Índice de Agua de Diferencia Normalizada NDWI, color azul más oscuro representa aguas más profundas. Resolución espacial var. $2 \mathrm{~m}$ a $10 \mathrm{~m}$.
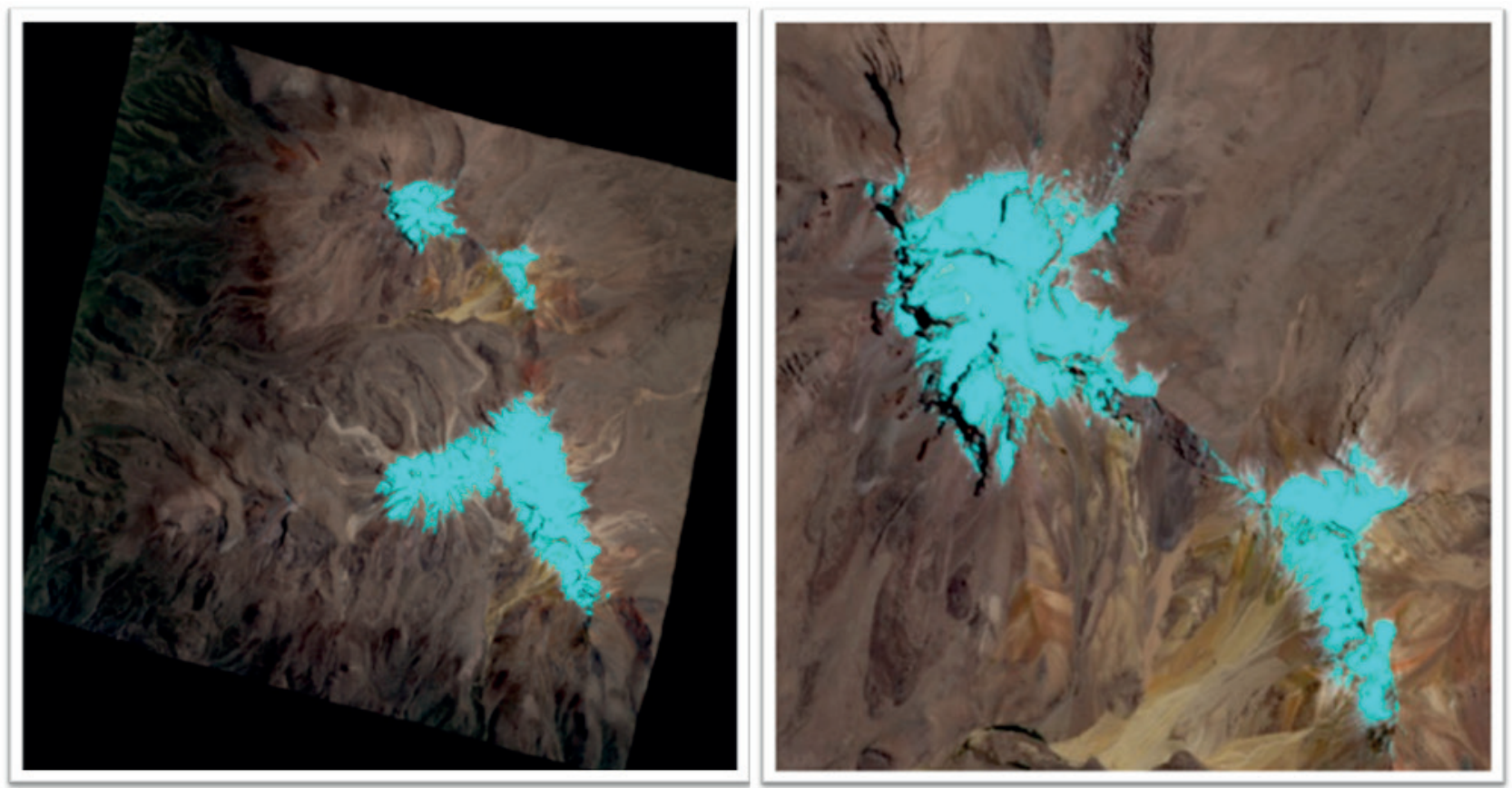

Figura 4. Índice de Nieve de Diferencia Normalizada NDSI, hielo y nieve de un celeste intenso. Resolución espacial var. $2 \mathrm{~m}$ a 10m.

diagnosticadas permiten identificar superficies o materiales de interés sobre el terreno.

Gracias a sus cualidades de automatización de procesos y la posibilidad de monitorear amplias regiones de terreno, es apropiado para estudios e ingeniería en ámbitos medioambientales y de prospección mineralógica.

\subsubsection{Obtención de anomalías espectrales por} presencia de óxidos

Las anomalías se obtuvieron aplicando la técnica de análisis de componente principales, útil en la determinación de óxidos (sulfuros meteorizados y otros ambientes) como indicios de mineralización en ciertos depósitos hidrotermales. Para resaltar las anomalías espectrales por 
presencia de Óxidos es necesario cubrir ciertas zonas en la imagen en proceso:

- Zonas de vegetación (NDVI u otros índices de vegetación)

- Zonas de agua, de nieve y sombras por pendiente. (NDWI, NDSI y valores mínimos del NIR)

- Zonas de saturación (máximos valores de zonas blancas en la banda BLUE).

Proporcionó muy buenos resultados para imágenes PeruSAT-1, resaltando zonas concretas de óxidos con alta resolución espacial.
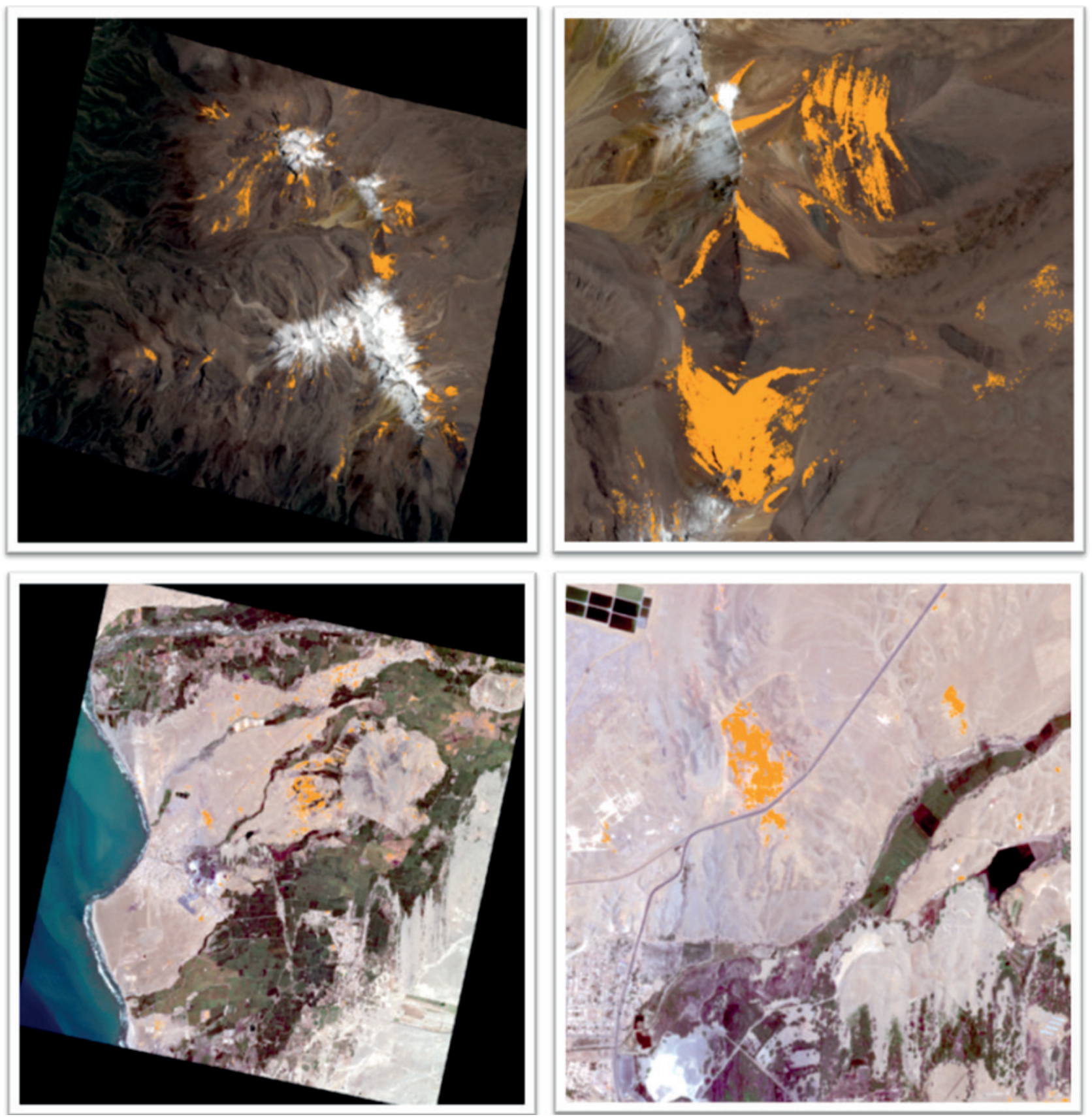

- Una de las aplicaciones es la identificación de zonas oxidadas para estudios de ambientes mineralizados a escalas locales y regionales. A través de imágenes o mosaico de imágenes (Ver Figura 5).

Resolución espacial var. $2 \mathrm{~m}$ a $10 \mathrm{~m}$.

\section{DISCUSIÓN}

La metodología del modelo de análisis de índices espectrales y obtención de anomalías espectrales con la técnica de análisis de componentes principales fue replicada de muchos sensores ampliamente validados

Figura 5. Anomalías espectrales por presencia de óxidos aplicando la técnica PCA. 
en el campo de la teledetección como lo son ASTER, SENTINEL-2 y LANDSAT-8 por mencionar algunos; metodología que generó buenos resultados de imágenes PeruSAT-1 para su alcance espectral. Es posible validar los resultados obtenidos comparándolos a los productos de sensores más solicitados en Teledetección, por clientes, en procesamiento de imágenes multi-espectrales, considerar referencia (INGEMMET, 2021) (Ver Figura 6).

\section{CONCLUSIONES}

- Queda demostrado la utilidad de la metodología del análisis para tratar imágenes satelitales obtenidas del sensor PerúSAT-1 y su aplicación en estudios y mapeos de alta resolución.

- Son varias las aplicaciones espectrales resultantes derivados y otras posibles, sin embargo, la cantidad y diversidad están limitadas por el alcance espectral, que para imágenes satelitales PerúSAT-1 se encuentra en el VNIR.

- Empleando el análisis de imágenes satelitales PerúSAT-1 de gran resolución espacial (var. $2 \mathrm{~m}$ a $10 \mathrm{~m}$ ) se pueden generar mapas de índices de vegetación, índice de agua, índice de nieve y anomalías espectrales por presencia de óxidos. Estos mapas son zonas a las que hay que prestar mucha atención, siendo las aplicaciones diversas en investigación e ingeniería.

- El estudio requiere una validación sobre el terreno para verificar la precisión; la facilidad de la metodología permite generar productos en tiempos cortos sobre gran extensión de área y los beneficios ligados a la aplicabilidad están relacionados a la agricultura, al recurso hídrico, al estudio de glaciares y el análisis de óxidos, entre otros.

- Comparando los resultados obtenidos de anomalías de óxidos a otros productos como SENTINEL-2 (incluso ASTER) se verificó gran porcentaje de similitud de las zonas resaltadas con valores máximos, sin embrago también hay diferencias en la distribución de resultados entre los sensores, sobre todo por el alcance espacial de cada uno, del cual PerúSAT-1 posee una mayor resolución.

\section{REFERENCIAS}

ALVARO PENTEADO CRÓSTA. (1993). Caracterização Espectral de Minerais de interesse à Prospecção Mineral e Sua Utilização em Processamento Digital de Imagens. In Anais VII Simpósio Brasileiro de Sensoriamento Remoto (pp. 202-210). http://marte.sid.inpe.br/col/dpi.inpe. br/marte@80/2008/06.05.17.13/doc/202-210.pdf

CONIDA. (2021). PerúSAT-1. Agencia Espacial Del Perú Ministerio de Defensa. https://www.gob.pe/institucion/ conida/noticias/324915-ministra-de-defensa-visito-laagencia-espacial-del-peru-conida

Crosta, A. P., \& Moore, J. M. (1989). Enhancement of Landsat Thematic Mapper imagery for residual soil mapping in SW Minais Gerais State, Brazil: A prospecting case history in Greenstone belt terrain. 7th Thematic Conference on Remote Sensing for Exploration Geology,
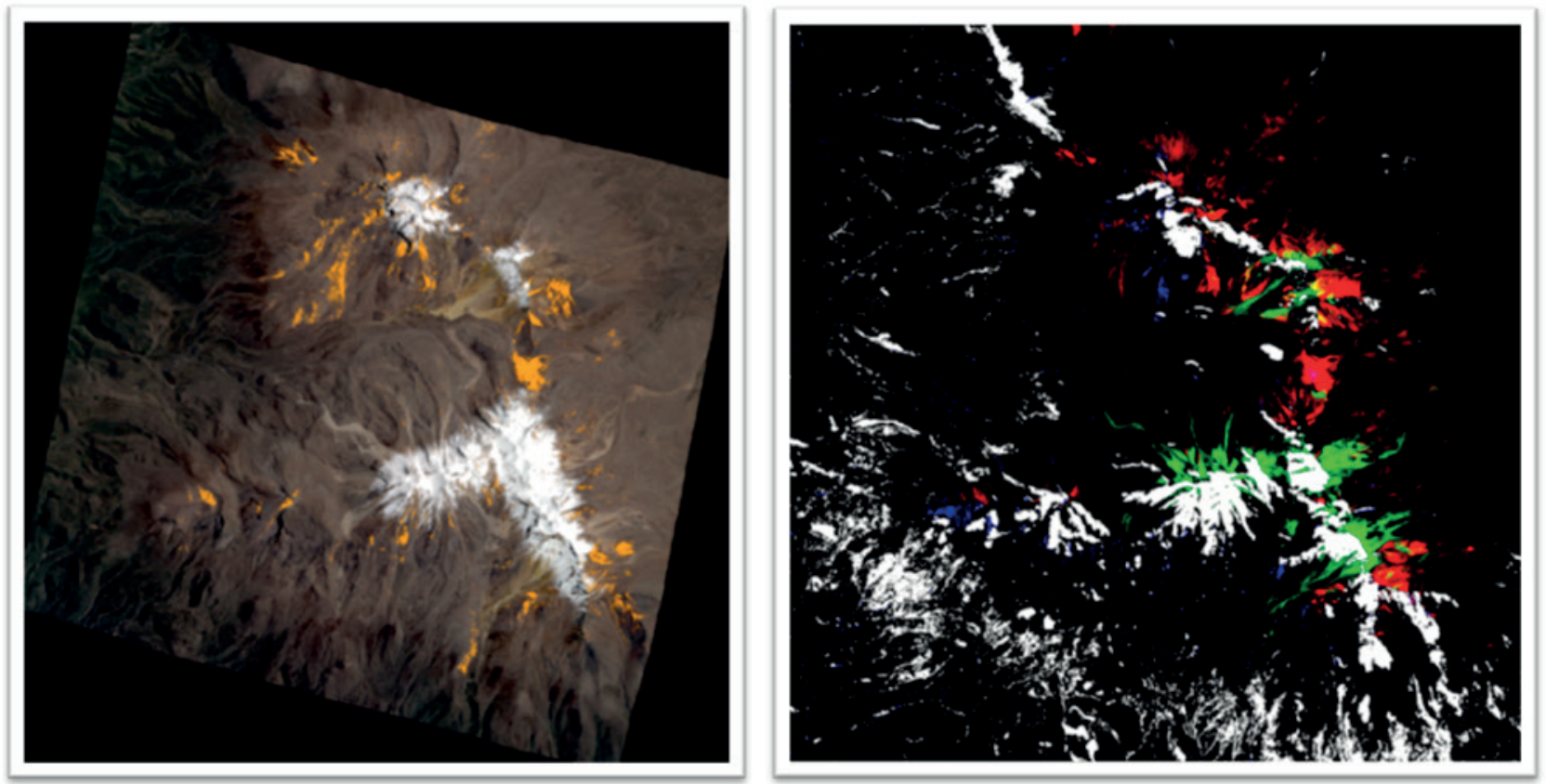

Figura 6. Comparación de anomalías espectrales por presencia de óxidos de imágenes PerúSAT-1 y composición RGB (férrico-arcillas-ferroso) de imágenes SENTINEL-2. Se observa mayor resolución para PerúSAT-1. 
1173-1187. https://pascal-francis.inist.fr/vibad/index. php?action=getRecordDetail\&idt=19663385

Harris Geospatial Solutions. (2021). Ecuaciones de indices espectrales. https://www.13harrisgeospatial.com/Company/ Events/Tradeshows/Spectral-Sessions

INGEMMET. (2021). Laboratorio de Teledetección GeoCATMIN. https://laboratorio.ingemmet.gob.pe/web/ lab/alcance tl

Loughlin, W. P. (1991). Principal component analysis for alteration mapping. Photogrammetric Engineering \& Remote Sensing, 57(9), 1163-1169. https://www.asprs.org/ wp-content/uploads/pers/1991journal/sep/1991 sep 1163 1169.pdfPeruSAT1. (2021). OrbiTrack imagen satelital. Lizard-Tail.Com, Centro Nacional de Operaciones de Imágenes Satelitales -CNOIS. http://www.lizard-tail.com/ isana/tracking/?catalog number $=41770$
U.S. Geological Survey. (2021). Spectral Index Equations. USGS, Landsat Science Teams, 3. https://www.usgs.gov/ core-science-systems/nli/landsat/landsat-science-teams?qtscience_support_page_related_con $=2 \# q t-s c i e n c e \_s u p p o r t$ page related_con 
